\title{
Hydrocortisone dosing in children with classic congenital adrenal hyperplasia: results of the German/Austrian registry
}

Heike Hoyer-Kuhn ${ }^{1}$, Angela Huebner ${ }^{2}$, Anette Richter-Unruh ${ }^{3}$, Markus Bettendorf ${ }^{4}$, Tilman Rohrer ${ }^{5}$, Klaus Kapelari $^{6}$, Stefan Riedl17, ${ }^{7}$ Klaus Mohnike ${ }^{9}$, Helmuth-Günther Dörr ${ }^{10}$, Friedrich-Wilhelm Roehl ${ }^{9}$, Katharina Fink ${ }^{11}$, Reinhard W Holl ${ }^{11}$ and Joachim Woelfle ${ }^{10}$

\author{
'Department of Paediatrics, Faculty of Medicine and University Hospital Cologne, University of Cologne, Cologne, Germany \\ ${ }^{2}$ Department of Paediatrics, University Children's Hospital Dresden, Dresden, Germany \\ ${ }^{3}$ University Children's Hospital Bochum, Bochum, Nordrhein-Westfalen, Germany \\ ¿University Children's Hospital Heidelberg, Heidelberg, Germany \\ ${ }^{5}$ University Children's Hospital Homburg, Homburg, Germany \\ ${ }^{6}$ University Children's Hospital Innsbruck, Innsbruck, Austria \\ ${ }^{7}$ Department of Pediatric, Medical University of Vienna, Vienna, Austria \\ ${ }^{8}$ St.Anna Kinderspital, Medical University of Vienna, Vienna, Austria \\ ${ }^{9}$ Department of Biometrics, Otto von Guericke Universität Magdeburg, Magdeburg, Sachsen-Anhalt, Germany \\ ${ }^{10}$ University Children's Hospital Erlangen, Erlangen, Germany \\ ${ }^{11}$ Institute of Epidemiology and Medical Biometry, ZIBMT, University of UIm, Ulm, Germany
}

Correspondence should be addressed to H Hoyer-Kuhn: heike-katharina.hoyer-kuhn@uk-koeln.de

\begin{abstract}
Objective: Treatment of classic congenital adrenal hyperplasia (CAH) is necessary to compensate for glucocorticoid/mineralocorticoid deficiencies and to suppress androgen excess. Hydrocortisone $(\mathrm{HC})$ is preferred in growing children with classic CAH but recommendations regarding dosage/administration are inconsistent. The aim of this study was to evaluate $\mathrm{HC}$ dosing in children with $\mathrm{CAH}$ in relation to chronological age, sex, and phenotype based on a multicenter CAH registry.

Design: The CAH registry was initiated in 1997 by the AQUAPE in Germany. On December 31st 2018, data from 1571 patients were included.

Methods: A custom-made electronic health record software is used at the participating centers. Pseudonymized data are transferred for central analysis. Parameters were selected based on current guidelines. Descriptive analyses and linear regression models were implemented with SAS 9.4.

Results: We identified 1288 patients on exclusive treatment with hydrocortisone three times daily (604 boys; median age 7.2 years; 817 salt-wasting phenotype, 471 simple-virilizing phenotype). The mean (lower-upper quartiles) daily HC dose $\left(\mathrm{mg} / \mathrm{m}^{2}\right.$ body surface area) was 19.4 (18.9-19.8) for patients $<3$ months $(n=329), 15.0(14.6-15.3)$ for age $\geq 3-12$ months $(n=463), 14.0(13.7-14.3)$ for age $1-5.9$ years $(n=745), 14.2(14.0-14.5)$ for age 6 years to puberty entry ( $n=669)$, and $14.9(14.6-15.2)$ during puberty to 18 years $(n=801)$. Fludrocortisone was administered in $74.1 \%$ of patients with a median daily dosage of $88.8 \mu \mathrm{g}$. Conclusion: Our analyses showed that still a high proportion of children are treated with $\mathrm{HC}$ doses higher than recommended. This evaluation provides comprehensive information on nationwide hydrocortisone substitution dosages in children with $\mathrm{CAH}$ underlining the benefit of systematic data within a registry to assess daily practice.
\end{abstract}
Key Words
- CYP21A2
- glucocorticoids
- fludrocortisone
treatment

https://ec.bioscientifica.com

https://doi.org/10.1530/EC-21-0023

(c) 2021 The authors Published by Bioscientifica Ltd

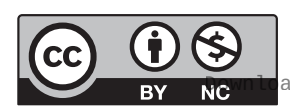

This work is licensed under a Creative Commons Attribution-NonCommercial 4.0 International License. ded from Bioscientifica.com at 04/26/2023 01:50:05PM
Endocrine Connections (2021) 10, 561-569 


\section{Introduction}

Classic congenital adrenal hyperplasia (CAH) is a hereditary autosomal recessive condition affecting adrenal steroidogenesis. Most of the cases (90-95\%) are caused by mutations in the 21-hydroxylase gene (CYP21A2) leading to altered cortisol synthesis with reduced cortisol levels in affected persons $(1,2)$. Additionally, aldosterone synthesis is impaired in about $75 \%$ of cases resulting in salt-wasting $\mathrm{CAH}$. The CAH form with salt-wasting is characterized as classic $\mathrm{CAH}(\mathrm{SW})$ whereas the form without saltwasting is called simple-virilizing CAH (SV) (3). CYP21A2 gene mutations are associated with a variety of clinical phenotypes depending on the residual 21-hydroxylase activity. Recently, genotype-phenotype associations were described in a large cohort of children with CAH from the AQUAPE CAH registry (4).

Treatment in classic CAH is necessary to compensate for glucocorticoid and mineralocorticoid deficiencies and also to blunt the ACTH secretion, the major driver of adrenal androgen production (5).

Oral glucocorticoid regimens aim to roughly mimic the physiological diurnal pattern but allow the ACTH suppression to escape in-between doses (6).

There are numerous reviews and guidelines available for the treatment of children with CAH $(7,8)$. Recently, it was stated in a Cochrane review that the evidence levels of the presented data were not strong enough to draw firm conclusions about the most effective glucocorticoid replacement scheme in CAH (8).

The current guideline from the Endocrine Society recommends, in growing individuals with classic $\mathrm{CAH}$, maintenance therapy with hydrocortisone $\left(10-15 \mathrm{mg} / \mathrm{m}^{2}\right.$ body surface area) (7). A questionnaire among ESPE members performed in 2000/2001 showed that most of the children with $\mathrm{CAH}$ were treated with hydrocortisone in higher doses (median dose between 13.75 and $17.5 \mathrm{mg} / \mathrm{m}^{2}$ BSA depending on age) than currently recommended (9).

Adequate dosing is impeded by the lack of a suitable low-dose HC preparation until recently, short halflife, fractional distribution of doses, differences in HC absorption and half-life, and increased cortisol clearance during puberty also influenced HC dosing.

The objective of this analysis was an evaluation of the administered hydrocortisone dosages in children from birth up to 18 years of age with classic CAH in Germany and Austria based on a nationwide registry (assessed period 1997-2018).

Additionally, age- and sex-related aspects were evaluated. HC dosages between children with or without salt-wasting were compared. Fludrocortisone dosages were also assessed in the whole cohort and according to the salt-wasting status and sex. Furthermore, aspects of overtreatment in case of a HC dosage above the recommended amount of $15 \mathrm{mg} / \mathrm{m}^{2}$ BSA were assessed (height, weight, BMI, and blood pressure). Participating centers were defined as big and small centers to assess the influence of the center size to treatment regimens.

Periods of treatment (before or after 2005 (introduction of neonatal screening in most regions)) were compared to assess the influence of the nationwide neonatal $\mathrm{CAH}$ screening and ensuing treatment recommendations.

\section{Patients and methods}

The AQUAPE (Arbeitsgemeinschaft für Qualitätssicherung in der pädiatrischen Endokrinologie/Working Group on Quality management in Pediatric Endocrinology) was started in 1997 in Magdeburg, Germany. The study (registry) was approved by the ethical committee of Saxony-Anhalt, Germany. Prospective follow-up data of patients with CAH were collected in a standardized database. Later, the German Society for Paediatric Endocrinology and Diabetology (DGKED) took responsibility for the registry (DGKED-QS)). Until now 49 centers have participated in the DGKED-QS registry. Centers were defined as big center if they cared for more than 19 patients; small centers were defined as centers caring for 19 or less patients. This definition was chosen based on the fact that with 19 patients as border nearly $50 \%$ of the patients have been treated in a big/small center. A custom-made electronic health record software is used at the participating centers for standardized documentation. Pseudonymized data are transferred for central analysis, including a validation step and a benchmarking report, twice yearly. The parameters were selected based on current treatment guidelines and are used for quality management and research. The data set includes data on phenotype, genotype, repetitive laboratory results, medication, anthropometric details, and surgical interventions.

All data were collected during routine care. Each participating center was initiated into the use of the documentation software after local ethic committee approval was obtained. Written consent has been obtained from each patient or subject after full explanation of the purpose and nature of all procedures used.

On December 31st 2018, the database included data from 1571 patients (705 male; 44.9\%). Patients receiving

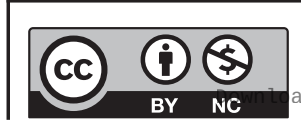


HC treatment only were selected, excluding patients on prednisolone or dexamethasone. Additionally, patients receiving $\mathrm{HC}$ in less than three dosages per day were excluded $(n=23)$. Finally, data of 1288 patients (simplevirilizing $\mathrm{CAH} n=471$; salt-wasting $\mathrm{CAH} n=817$; type of CAH was entered in the database by the local treating physician based on clinical aspects) with an age $\leq 18$ years, who received three doses of hydrocortisone per day, and with complete anthropometric details were included in the analysis.

Age, sex, weight, length/height, BMI, hydrocortisone dosage, body surface area, daily split of dosage, phenotype, blood pressure, and information on additional fludrocortisone treatment were included in the assessment. Body surface area was calculated according to the formula by Dubois and Dubois (10). Overall, 45 centers from Germany and 4 centres from Austria contributed longitudinal data to this analysis. Age groups were defined as follows: children from birth (first day of treatment) to 3 months of age, $\geq 3$ months to 12 months, 1 year to 5.9 years, 6 years up to onset of puberty (Tanner stage B2 in girls; testicular volume $>3 \mathrm{~mL}$ in boys), and pubertal children up to 18 years of age. In this longitudinal analysis, individual patients could contribute to several age groups, with appropriate statistical modeling of dependencies.

HC dosages were also evaluated in relation to two time periods, before January 1st 2005 and afterwards). The 2005 cut-off was chosen, as it was assumed that in 2005 most areas in Germany had implemented the neonatal CAH screening.

\section{Statistical analysis}

Continuous variables were aggregated as median, upper and lower quartiles. Categorical data were assessed as percentages. General linear regression models were used to compare hydrocortisone requirement by age-group, by age and sex, and for patients with or without fludrocortisone therapy. To analyze hydrocortisone requirement for patients treated before and after 2005, a general linear regression model adjusted for age-group and interaction was used. Repeated measurements per subject were taken into account using first-order autoregressive covariance structure. This model was used to accommodate the fixed effects of treatment and time and the covariation between repeated measures data on the same subject at different times (11). To adjust for multiple comparisons, TukeyKramer test was used. Data were not additionally adjusted for BMI as length/height and weight are the basis for the body surface area calculation, which then would have been included in the model twice. In clinical routine, HC dosing according to $\mathrm{m}^{2}$ body surface area is recommended, why this parameter was chosen? Estimated means and 95\% CI were calculated. A $P$-value $<0.05$ was defined as statistically significant. Statistical analysis was performed with SAS-version 9.4 build TS1M5 in batch mode (Statistical Analysis Systems, SAS Institute Inc., Cary, NC, USA) on a Windows-Server 2016 mainframe computer.

\section{Results}

Until December 2018, 1288 patients treated three times daily exclusively with $\mathrm{HC}$ were included in the registry. A salt-wasting form of CAH was documented in 817 patients, whereas 471 were classified as simple-virilizing CAH. Out of 49 participating centers, 42 were defined as small centers ( $86 \%$, number of patients, $n=724)$, and 7 as big centers (14\%, number of patients, $n=564)$.

The median age of the cohort was 7.2 years (3.7-10.7), the median age of start of puberty in girls was 10.18 years, in boys 10.99 years. The whole cohort presented with a median height of -0.02 SDS $(-0.81-0.72)$ and a median weight of 0.51 SDS (-0.28-1.32). Forty-seven percent of the patients were male. Additional characteristics of the patients are shown in Table 1.

The median daily hydrocortisone dosage per $\mathrm{m}^{2}$ body surface area (BSA) was $14.4 \mathrm{mg}(12.3-16.7)$ for patients between birth (age at first documented dose was the day of birth) and 18 years. The absolute median HC dosage depending of the time of day was $6.9 \mathrm{mg}$ (5.6-8.3) in the morning, $3.5 \mathrm{mg}(2.8-4.4)$ at midday, and $3.8 \mathrm{mg}$ (3.0-4.70) in the evening.

The estimated mean dosages differed significantly between the different age groups: after adjustment for sex differences, the highest estimated dose was given in the youngest age group (0-3 months): 19.4 (18.9$19.8) \mathrm{mg}(n=329)$ in comparison with all other groups $(P<0.0001)$, whereas the HC dosages in the other groups were not statistically different: $15.0(14.6-15.3)(\geq 3-12$ months; $n=463), 14.0$ (13.7-14.3) ( $1-5.9$ years; $n=745)$, $14.2(14.0-14.5)$ (6 years-onset of puberty; $n=669)$ and 14.9 (14.6-15.2) (puberty-18 years; $n=801$ ). Comparing the estimated mean $\mathrm{HC}$ doses $/ \mathrm{m}^{2}$ BSA between the prepubertal group and the pubertal group reveals a slight but significant increase from $14.2^{2}$ to $14.9 \mathrm{mg} / \mathrm{m}^{2}$ $(P<0.0001)$. The median age of start of puberty in girls was 10.18 years, in boys 10.99 years.

Additionally, the mean HC doses according to age and time of day are presented in Figs 1 and 2. 
Table 1 Patient characteristics with classic CAH and hydrocortisone treatment.

\begin{tabular}{|c|c|}
\hline Characteristic & Value \\
\hline Total number of included patients $(n)$ & 1288 \\
\hline Male $n(\%)$; Female $n(\%)$ & 604 (46.9); 684 (53.1) \\
\hline Salt-wasting $\mathrm{CAH} n(\%)$ & $817(63.4)$ \\
\hline Simple-virilizing $\mathrm{CAH} n(\%)$ & $471(36.6)$ \\
\hline BSA m² (median (lower-upper quartile)) & $1.0(0.7-1.4)$ \\
\hline Age 0 -3months $(n)$ & 329 \\
\hline Age $\geq 3-12$ months $(n)$ & 463 \\
\hline Age $1-5.9$ years $(n)$ & 745 \\
\hline Age 6-entry puberty years $(n)$ & 669 \\
\hline Age pubertal-18 years $(n)$ & 801 \\
\hline Hydrocortisone: $n(\%)$ & $1288(100)$ \\
\hline Fludrocortisone: $n(\%)$ & $955(74.1)$ \\
\hline
\end{tabular}

BSA, body surface area.

To demonstrate differences between boys and girls, the cohort was divided according to sex. Included were 604 boys with a median age of 6.8 years (3.1-10.5) and 684 girls with a median age of 7.7 (4.4-11.0) years. Adjusting for age, estimated mean HC dosages did not differ significantly between boys and girls in the whole cohort (boys: $15.5 \mathrm{mg}$ (15.1-1587) vs girls $15.5 \mathrm{mg}$ (15.315.8); $P=0.6571)$. Further results of the mean HC dosages according to sex and age groups are presented in Table 2.

Additionally, mean $\mathrm{HC}$ doses adapted to age groups and phenotype of CAH are presented in Table 2.

Out of all patients on HC, 74.1\% $(n=955)$ received additional fludrocortisone (FC) with a median dosage of 88.8 (71.9-116.7) $\mu \mathrm{g}$ per day. Patients with FC treatment $(n=955)$ displayed a median age of 6.1 years (2.8-9.7) (50.2\% male) vs 10.3 years (7.6-12.3) in the group without

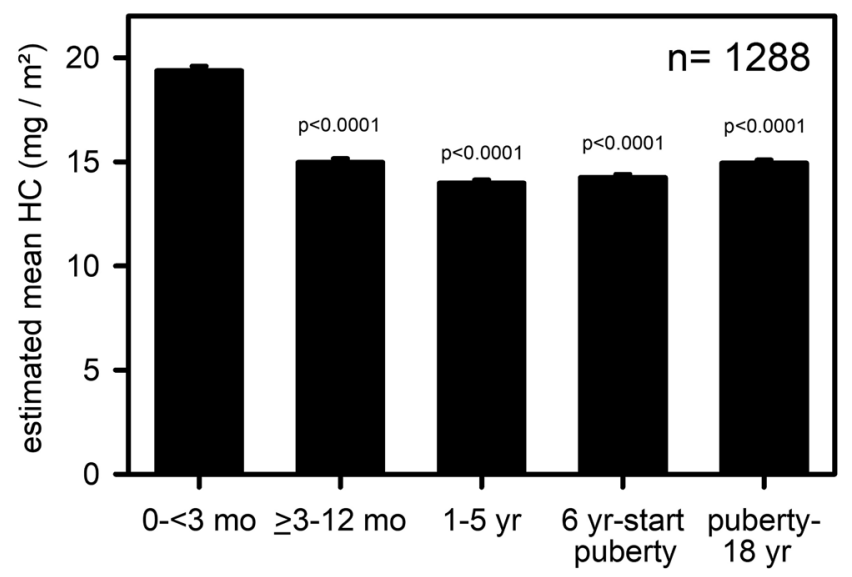

Age-group

Figure 1

Hydrocortisone dosages in children with congenital adrenal hyperplasia according to age.
FC treatment ( $n=333 ; 37.5 \%$ male). Out of 604 boys, 479 (79.3\%) were treated additionally with FC in a median dosage of 87.5 (72.0-119.8) $\mu \mathrm{g}$ per day, whereas $6965 \%$ (476 out of 684) of the girls received FC in a median dosage of 90.0 (71.9-115.2) $\mu \mathrm{g}$ daily.

In the FC treated group, 789 patients were classified as patients with SW-CAH and 166 patients classified as SV-CAH. In the group without FC treatment, 28 were classified as SW-CAH patients, and 305 as SV-CAH patients.

Further results on $\mathrm{HC}$ requirement according to $\mathrm{FC}$ use and clinical phenotype are presented in Figs 3 and 4.

The percentage of overtreated patients defined by an applicated $\mathrm{HC}$ dosage of $>15 \mathrm{mg} / \mathrm{m}^{2}$ BSA was in the age group $0-3$ months $73.3 \%$, in the age group $\geq 3-12$ months $37.6 \%$, 1-5.9 years 33.6\%, 6 years-onset of puberty $38.3 \%$, and puberty-18 years $50.6 \%$. Taking into account the whole cohort, $44.1 \%$ of the patients received an overtreatment, and still $41 \%$ an overtreatment excluding the age group of $0-3$ months.

Comparing patients in the different age groups according to overtreatment on different clinical parameters were presented in the following: BMI SDS was significantly different in the age group 0-3 months $(P=0.0116$, $(\geq 3-12$ months $(P<0.0010), 1-5.9$ years $(P=0.0060), 6$ years-onset of puberty $(P=<0.0037)$, and puberty-18 years $(P=0.0198)$.

No significant differences in height SDS according to dosage and age were detected: in the age group 0-3 months $P=0.9436$, age group $\geq 3-12$ months $P=0.1316$, $1-5.9$ years $P=0.5950,6$ years-onset of puberty $P=0.9774$, and puberty-18 years $P=0.0966$.

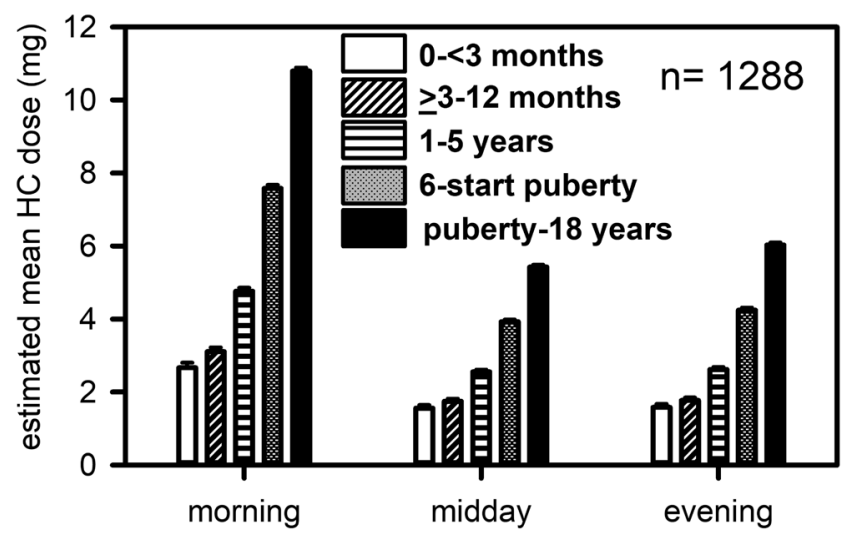

Time of Day

Figure 2

Hydrocortisone dosages in children with congenital adrenal hyperplasia according to time of day.

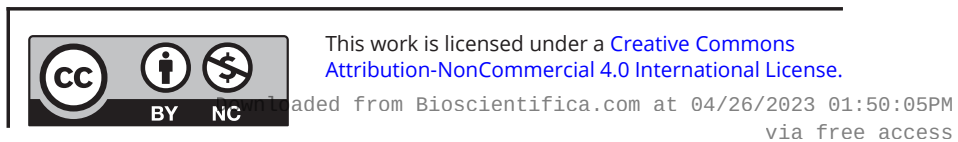


Table 2 Differences in Hydrocortisone dosages ( $\left.\mathrm{mg} / \mathrm{m}^{2} \mathrm{BSA}\right)$ according to age between boys and girls and salt-wasting/simplevirilizing type of $\mathrm{CAH}$; data given as estimated mean and $95 \% \mathrm{CI}$.

\begin{tabular}{l} 
Age group \\
\hline $0-<3$ months \\
$\geq 3-12$ months \\
$1-5.9$ years \\
6-start of puberty \\
Puberty-18 years
\end{tabular}

Boys
$18.52(17.91-19.13)$
$14.49(13.98-14.99)$
$13.95(13.53-14.36)$
$14.44(14.01-14.87)$
$15.23(14.79-15.68)$

\begin{tabular}{c} 
Girls \\
\hline $20.22(19.61-20.83)$ \\
$15.47(14.96-15.98)$ \\
$14.00(13.59-14.42)$ \\
$14.08(13.68-14.49)$ \\
$14.72(14.34-15.10)$ \\
\hline
\end{tabular}

The levels for systolic and diastolic blood pressure according to hydrocortisone dosage were not significantly different in the five age groups. Comparison of the prescribed HC dosages in small vs big centers revealed a statistical significant higher mean HC dosage in small centers with $15.7 \mathrm{mg} / \mathrm{m}^{2}$ BSA (15.4-16.0) vs $15.3 \mathrm{mg} / \mathrm{m}^{2}$ BSA (14.9-15.6) in big centers.

We found a statistically significant difference between the administered HC dosages in relation to the period before or after introduction of general screening for $\mathrm{CAH}$ (calendar year 2005). Before 2005, the adjusted mean dosage was 16.4 (16.1-16.7) $\mathrm{mg} \mathrm{HC}$ per $\mathrm{m}^{2} \mathrm{BSA}$ and after 2005 the dosage was 14.6 (14.3-14.9) $\mathrm{mg}$ HC per $\mathrm{m}^{2} \mathrm{BSA}$ $(P<0.0001)$.

\section{Discussion}

We present hydrocortisone dosages in children with classic CAH according to age, sex, daytime, phenotype, and additional fludrocortisone treatment. Our real-world data reveal a preponderance of the salt-wasting phenotype as expected based on previous case-series.

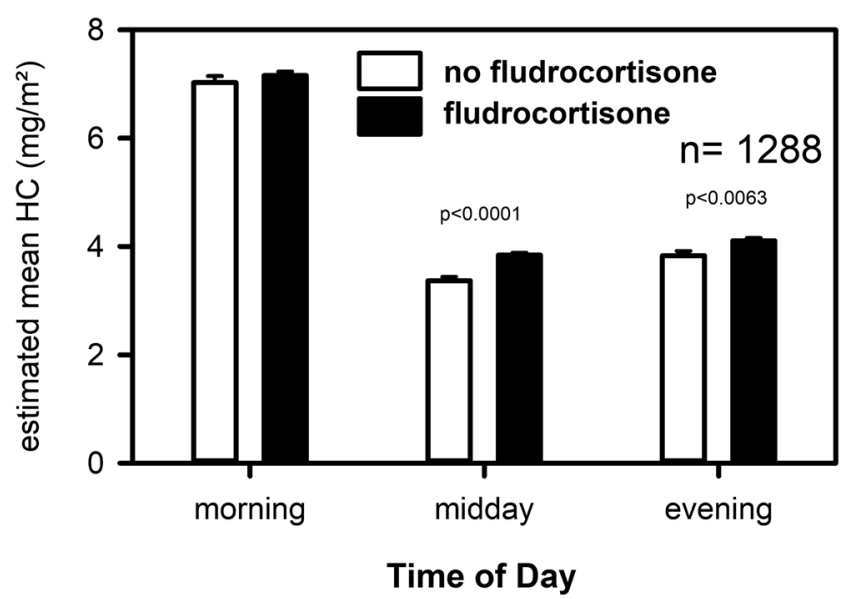

Figure 3

Hydrocortisone dosages in children with congenital adrenal hyperplasia according to additional fludrocortisone treatment and time of day.

\begin{tabular}{|c|c|c|c|}
\hline p value & Salt-wasting & Simple-virilizing & p value \\
\hline 0.0046 & مכ-2ح 19) & $17.36(16.3$ & 018 \\
\hline 0.1733 & $15.06(14$ & & 40 \\
\hline 1.000 & $13.90(13.56-14.26)$ & $14.27(13.74-14.81)$ & 0.9937 \\
\hline 0.9757 & $14.31(13.94-14.68)$ & $14.29(13.81-14.77)$ & 1.000 \\
\hline 0.7816 & $15.42(15.04-15.81)$ & $14.24(13.81-14.67)$ & 0.0070 \\
\hline
\end{tabular}

There are different glucocorticoid preparations used in order to normalize androgen secretion and to achieve sufficient glucocorticoid levels in affected patients $(12,13$, 14). Depending on the preparation used, different effects on growth pattern and final height have been detected and published previously $(12,13,14)$. As HC therapy is the standard of care for pediatric patients $(12,15,16)$, we selected 1311 patients exclusively on HC among 1571 patients in the registry. Out of these 1288 received HC three times daily and therefore have been included in our analyses. Furthermore, 260 children (16.5\%) treated with other preparations such as prednisolone or dexamethasone were excluded.

The median daily $\mathrm{HC}$ dosage, including all age groups, of $14.4 \mathrm{mg} / \mathrm{m}^{2}$ BSA is within the current recommended range of substitution between $10-15 \mathrm{mg} / \mathrm{m}^{2}$ BSA (7). The median dosage also implies that $44 \%$ of all patients $41 \%$ of the patients older than 3 months) received a dosage higher than $15 \mathrm{mg} / \mathrm{m}^{2} \mathrm{BSA}$, which represents overdosage according to guidelines. Division of HC into three daily doses is generally recommended. In our cohort this regimen seems to be implemented in most cases as 1288 out of 1311 patients received three HC dosages per day.

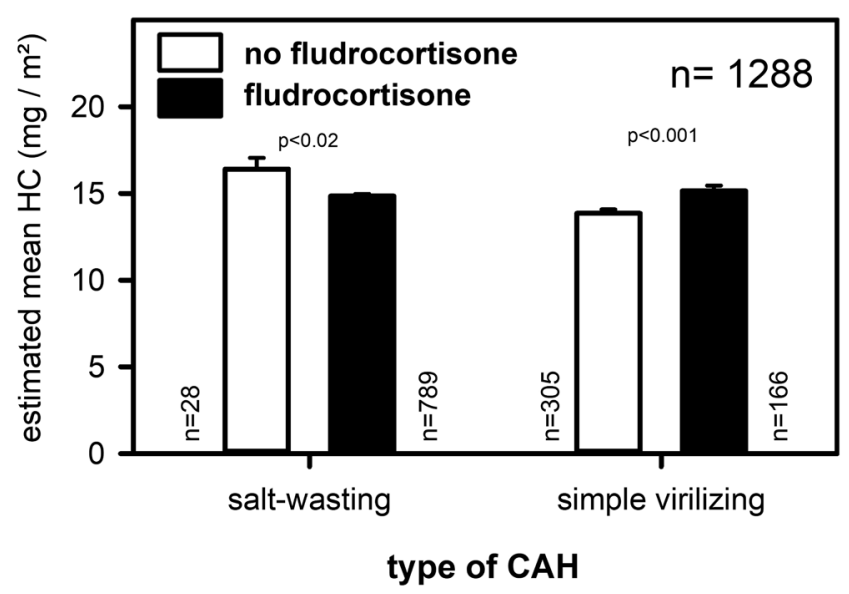

Figure 4

Hydrocortisone dosages in children with congenital adrenal hyperplasia according to additional fludrocortisone treatment and salt-wasting status.

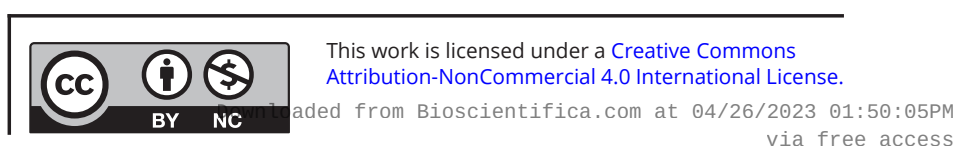


The morning dosage is the highest dosage in the whole cohort as well as in all different age groups.

A significant decrease in the calculated mean HC dose after the first three months of age could be found. To the best of our knowledge, there is no evidence that higher dosages in the neonatal period reduce lifethreatening events (17). Furthermore, there are different trials available showing an association between high dose glucocorticoid treatment and short stature in adulthood $(15,18,19,20)$. On the one hand one might speculate that there is a rationale behind higher neonatal HC dosages based on the fast increase in body weight and BSA in the first months of life with the need for continuous follow-up and frequent dosage adjustments to reduce the risk of insufficient glucocorticoid substitution. On the other side one could argue that the higher dosages are not prescribed deliberately but there is just an inadequate dose adjustment in the youngest children due to absent adequate weight adjusted preparations in the past. Therefore one could assume that a high hydrocortisone dosage in newborns and young children is accepted due to fast growing during that age. These remarks are not proven but try to explain the higher dosages which are not tolerable in the future due to the known side effects of an overtreatment mentioned also in this discussion.

Additionally, up until May 2015 the only approved HC tablets available in Germany were $10 \mathrm{mg}$ HC tablets, these were inadequate for precise dosing especially in newborns with a BSA $\sim 0.2 \mathrm{~m}^{2}$.

A common treatment approach was the substitution with $3 \times 2.5 \mathrm{mg}$ per day (a quarter tablet) in newborns which resulted in a dosage of $\sim 37.5 \mathrm{mg} / \mathrm{m}^{2}$ assuming a BSA of $0.2 \mathrm{~m}^{2}$. Alternatively, custom-made preparations are used. An international web-based survey about the types of medication in children with adrenal insufficiency (AI) revealed that the majority of children received a compounded medication with a high variability of contained HC (21). In May 2015 a new commercially available HC preparation was approved for HC substitution in newborns and children up to 18 years (Alkindi ${ }^{\circledR}$ with 1,2 or $5 \mathrm{mg} \mathrm{HC}$ as granules in capsules for opening, Diurnal Company, UK) (22). Hydrocortisone granules were commercially available since February 2018. In 2020 results of a prospective pediatric trial from Neumann et al. were published presenting that this pediatric licensed drug formulation in form of granula allowing a weight adapted dosing results in a lower daily dose in children age $0-8$ years compared to our data (23).

The HC dosage was significantly higher in pubertal children which might depend on an altered endocrine milieu in pubertal children. Different studies have described alterations of the cortisol clearence, half-life of free cortisol, and insulin resistance leading to a reduction of the treatment efficacy due to an increased androgen secretion in pubertal children $(24,25,26)$.

The analyses comparing the percentage of patients treated with an overdosage and patients receiving a dosage in the recommended range of $10-15 \mathrm{mg} \mathrm{HC} / \mathrm{m}^{2}$ BSA demonstrated no clear pattern in our cohort regarding BMI/height SDS/weight SDS and blood pressure. At the moment no data about the final height in association to the absolute amount of $\mathrm{HC}$ of the individual patient received over the childhood are available out of our registry. However, one has to keep in mind that it was shown by other groups that a HC dosage exceeding $17 \mathrm{mg} / \mathrm{m}^{2}$ BSA during puberty could reduce final height in children with $\mathrm{CAH}$ (18). Therefore the presented data on overdosing should initiate a (re-)debate on dosing and weight adjusted $\mathrm{HC}$ preparations in the participating centers.

Comparing HC dosages between boys and girls revealed no significant difference. Interestingly, girls receive a higher dose in the first year of life whereas this trend reverses subsequently. For that phenomenon no clear explanation is available to the best of our knowledge. No recommendations for different dosages in boys vs girls are available. Therefore it might also be an incidental finding. Changing practices on salt supplementation in SW-CAH have recently been published based from this registry (27). Evaluation of sodium chloride supplementation revealed an increasing use of sodium chloride supplementation in the period from 1999 to 2015, but sodium chloride supplementation had no influence on the dosages of HC and FC (27). Because mineralocorticoids also have a glucocorticoid effect, one could assume that children with SW-CAH receiving FC need lower HC dosages. However, our results showed a significant difference of HC dosages with even a higher HC dosage in the group with additional FC treatment compared to the group treated with HC only.

In our cohort 28 children with a documented salt-wasting type of $\mathrm{CAH}$ have not been treated with additional FC, which would be expected in SW-CAH. However, the diagnosis of salt-wasting is still challenging and might be based on clinical (vomiting), laboratory (low serum sodium) or genetic data, however the genotypephenotype correlation in CAH is not consistent in 100\% of the cases as it could be shown previously in our registry (4). It should be kept in mind that in the registry the type of $\mathrm{CAH}$ was entered by the treating physician based on clinical aspects. This might explain the results

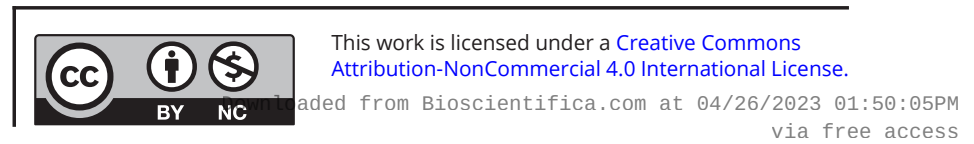


showing children defined as patients with SW-CAH but without FC treatment which is implausible in the view of the authors.he evaluation of patients treated before 2005 or after 2005 revealed a significant downward trend in the total daily dose of $\mathrm{HC}$, which goes along with the updated recommendations from the Endocrine Society to treat with the lowest effective dosage (7). Additionally, the neonatal $\mathrm{CAH}$ screening causes an early diagnosis of the affected patients and the adaptation of adequate treatment concepts and prescribed dosages of HC (15).

\section{Limitations}

Our results are limited by different aspects discussed here: The centres involved in the registry differ in the number of CAH patients they care for. Therefore the structure of care and the experience in treating children with $\mathrm{CAH}$ might be quite different leading to heterogeneous treatment approaches.

The data are entered by each center in the database without financial compensation which might have led to delayed and incomplete data entry.

The information available in the registry is predefined and necessarily limited. For example, there is no information about the precise time of day the HC dosages were administered (only the information morningmidday-evening is available), this information would have been interesting for discussion of dosages according to age.

Furthermore the results of dosage and overdosage should trigger a discussion about the best HC formulation for children with CAH. Additionally, the monitoring concept for children with $\mathrm{CAH}$ might be included in these discussions (e.g. frequency of visits based on age, saliva sampling for all patients). o information about the type of administered $\mathrm{HC}$ formulations is available yet. The database should offer new entry options to analyze for example, the influence of the applicated HC formulation in the future. At present benchmarking reports are send to all participating centers twice a year. These reports might be a useful tool for treatment improvement and standardization.

$\mathrm{CAH}$ is one of approximately 5000-8000 known rare diseases that affect about $6 \%$ of the population. Standardized medical care is still not accessible for all patients and research activities in the field of rare diseases are challenging. To the best of our knowledge, there are only a few national and cross-border/international registries and from these only a few systematic publications in the field of CAH $(28,29,30,31)$. The German CAH registry was started more than twenty years ago and contains therefore data from $>1500$ patients representing one of the largest cross-border CAH registries. This fact strengthens the value of our analysis.

In summary this large, multicentre evaluation provides comprehensive information on real life - doses for hydrocortisone substitution in children with CAH. Though different theoretical considerations are published regarding $\mathrm{HC}$ dosages according to e.g. age, sex, type of CAH or concomitant FC treatment, our results present the real-world practice in a cohort of $>1500$ children and adolescents with CAH. Future long-term data could evaluate the effect of newly approved $\mathrm{HC}$ formulations for pediatric patients with respect to final height, prescribed dosages, and numbers of adrenal crises. Intermittent evaluation of the documented data in a registry gives the chance to critically assess current care and treatment outcome. Adaptation and continuation of a registry such as the German CAH registry seems to be worthwhile as it contains systematic data of children with a rare disease and provides insights into the daily practice of a large cohort. In the future, the German/Austrian registry plans to cooperate closely with international registries, for example the European ERN I-DSD/I-CAH registries (29).

\section{Declaration of interest}

The authors declare that there is no conflict of interest that could be perceived as prejudicing the impartiality of the research reported.

\section{Funding}

This analysis was supported by a grant to the German Society for Pediatric Endocrinology and Diabetology (DGKED) by Diurnal Limited (Cardiff; United Kingdom).

\section{Author contribution statement}

F-W Röhl, K Mohnike, K Fink, R W Holl carried out study design and project management. Scientific discussion of study results was done by M Bettendorf, H-G Dörr, A Huebner, K Kapelari, A Richter-Unruh, S Riedl, T Rohrer, and J Woelfle. Data analysis was done by K Fink, R W Holl, and H Hoyer-Kuhn. Preparation of the manuscript was done by $\mathrm{H}$ Hoyer-Kuhn. Editing and final approval of the manuscript were done by all authors.

\section{Acknowledgements}

The thank the following centers for contributing data to the DGKED-CAHregistry: Aue Kinderklinik, Berlin Charite Unikinderklinik, Berlin Lichtenberg, Bielefeld Evangelisches Krankenhaus, BochumEndokrinologikum Ruhr, Bonn Unikinderklinik, Bremen-Nord Kinderklinik, Chemnitz Kinderklinik, Cottbus Kinderarztpraxis, Dornbirn Kinderklinik, Dresden Gemeinschaftspraxis, Dresden Universitäts-Kinderklinik, Erlangen Universitäts-Kinderklinik, Essen Universitätskinderklinik, Frankfurt Universitätskinderklinik, Freiburg Universitätskinderklinik, Greifswald Universitätskinderklinik, Halle/ Saale, Kinderklinik, Hamburg Kinder-MVZ am Wilhelmstift, Hamburg MVZ Dr Commenz, Hannover Medizinische Hochschule, Heidelberg Praxis, Heidelberg Universitäts-Kinderklinik, Hildesheim St. Bernward Kinderklinik, 
Homburg Universitäts-Kinderklinik, Innsbruck Universitäts-Kinderklinik, Jena Universitäts-Kinderklinik, Kiel Universitäts-Kinderklinik, Krefeld Kinderklinik, Köln Praxis Dr Korsch, Köln Unikinderklinik, Leipzig UniversitätsKinderklinik, Lübeck Universitäts-Kinderklinik, Magdeburg UniversitätsKinderklinik, Magdeburg städtische Kinderklinik, München Haunersche KiKlinik, München-Gauting Kinderarztpraxis, München-Schwabing, Münster Universitätskinderklinik, Nürnberg Cnopfsche Kinderklinik, Oldenburg Endokrinologisches MVZ Pädiatrie, Paderborn Kinderklinik, Rotenburg Kinderklinik, Stade Elbekliniken Kinderklinik, Tübingen UniversitätsKinderklinik, Ulm Endokrinologikum, Ulm Universitäts-Kinderklinik, Wels Kinderklinik, Wien Universitätskinderklinik.

\section{References}

1 Krone N, Dhir V, Ivison HE \& Arlt W. Congenital adrenal hyperplasia and P450 oxidoreductase deficiency. Clinical Endocrinology 200766 162-172. (https://doi.org/10.1111/j.1365-2265.2006.02740.x)

2 White PC, New MI \& Dupont B. HLA-linked congenital adrenal hyperplasia results from a defective gene encoding a cytochrome P-450 specific for steroid 21-hydroxylation. PNAS $1984 \mathbf{8 1}$ 7505-7509. (https://doi.org/10.1073/pnas.81.23.7505)

3 White PC \& Speiser PW. Congenital adrenal hyperplasia due to 21-hydroxylase deficiency. Endocrine Reviews 200021 245-291. (https://doi.org/10.1210/edrv.21.3.0398)

4 Riedl S, Rohl FW, Bonfig W, Bramswig J, Richter-Unruh A, Fricke-Otto S, Bettendorf M, Riepe F, Kriegshauser G, Schonau E, et al. Genotype/ phenotype correlations in 538 congenital adrenal hyperplasia patients from Germany and Austria: discordances in milder genotypes and in screened versus prescreening patients. Endocrine Connections 20198 86-94. (https://doi.org/10.1530/EC-18-0281)

5 Turcu AF \& Auchus RJ. Novel treatment strategies in congenital adrenal hyperplasia. Current Opinion in Endocrinology, Diabetes, and Obesity 201623 225-232. (https://doi.org/10.1097/ MED.0000000000000256)

6 Debono M, Mallappa A, Gounden V, Nella AA, Harrison RF, Crutchfield CA, Backlund PS, Soldin SJ, Ross RJ \& Merke DP. Hormonal circadian rhythms in patients with congenital adrenal hyperplasia: identifying optimal monitoring times and novel disease biomarkers. European Journal of Endocrinology 2015173 727-737. (https://doi.org/10.1530/EJE-15-0064)

7 Speiser PW, Arlt W, Auchus RJ, Baskin LS, Conway GS, Merke DP, Meyer-Bahlburg HFL, Miller WL, Murad MH, Oberfield SE, et al. Congenital adrenal hyperplasia due to steroid 21-hydroxylase deficiency: an Endocrine Society clinical practice guideline. Journal of Clinical Endocrinology and Metabolism 2018103 4043-4088. (https:// doi.org/10.1210/jc.2018-01865)

$8 \mathrm{Ng}$ SM, Stepien KM \& Krishan A. Glucocorticoid replacement regimens for treating congenital adrenal hyperplasia. Cochrane Database of Systematic Reviews 20203 CD012517. (https://doi. org/10.1002/14651858.CD012517.pub2)

9 Riepe FG, Krone N, Viemann M, Partsch CJ \& Sippell WG. Management of congenital adrenal hyperplasia: results of the ESPE questionnaire. Hormone Research 200258 196-205. (https://doi. org/10.1159/000065492)

$10 \mathrm{Du}$ Bois D \& Du Bois EF. A formula to estimate the approximate surface area if height and weight be known. 1916. Nutrition 19895 303-311; discussion 12-13.

11 Littell RC, Pendergast J \& Natarajan R. Modelling covariance structure in the analysis of repeated measures data. Statistics in Medicine 200019 1793-1819. (https://doi.org/10.1002/10970258(20000715)19:13<1793::aid-sim482>3.0.co;2-q)

12 Punthakee Z, Legault L \& Polychronakos C. Prednisolone in the treatment of adrenal insufficiency: a re-evaluation of relative potency. Journal of Pediatrics 2003143 402-405. (https://doi. org/10.1067/S0022-3476(03)00294-4)
13 Rivkees SA \& Crawford JD. Dexamethasone treatment of virilizing congenital adrenal hyperplasia: the ability to achieve normal growth. Pediatrics 2000106 767-773. (https://doi.org/10.1542/peds.106.4.767)

14 Sarafoglou K, Gonzalez-Bolanos MT, Zimmerman CL, Boonstra T, Yaw Addo O \& Brundage R. Comparison of cortisol exposures and pharmacodynamic adrenal steroid responses to hydrocortisone suspension vs. commercial tablets. Journal of Clinical Pharmacology 201555 452-457. (https://doi.org/10.1002/jcph.424)

15 Bonfig W, Bechtold S, Schmidt H, Knorr D \& Schwarz HP. Reduced final height outcome in congenital adrenal hyperplasia under prednisone treatment: deceleration of growth velocity during puberty. Journal of Clinical Endocrinology and Metabolism 200792 1635-1639. (https://doi.org/10.1210/jc.2006-2109)

16 Clayton PE, Miller WL, Oberfield SE, Ritzen EM, Sippell WG, Speiser PW. Consensus statement on 21-hydroxylase deficiency from the european society for paediatric endocrinology and the lawson wilkins pediatric endocrine society. Hormone Research $2002 \mathbf{5 8}$ 188-195. (https://doi.org/10.1159/000065490)

17 El-Maouche D, Arlt W \& Merke DP. Congenital adrenal hyperplasia. Lancet 2017390 2194-2210. (https://doi.org/10.1016/S01406736(17)31431-9)

18 Bonfig W, Pozza SB, Schmidt H, Pagel P, Knorr D \& Schwarz HP. Hydrocortisone dosing during puberty in patients with classical congenital adrenal hyperplasia: an evidence-based recommendation. Journal of Clinical Endocrinology and Metabolism 200994 3882-3888. (https://doi.org/10.1210/jc.2009-0942)

19 Grigorescu-Sido A, Bettendorf M, Schulze E, Duncea I \& Heinrich U. Growth analysis in patients with 21-hydroxylase deficiency influence of glucocorticoid dosage, age at diagnosis, phenotype and genotype on growth and height outcome. Hormone Research 200360 84-90. (https://doi.org/10.1159/000071876)

20 Van der Kamp HJ, Otten BJ, Buitenweg N, De Muinck KeizerSchrama SM, Oostdijk W, Jansen M, Delemarre-de Waal HA, Vulsma T \& Wit JM. Longitudinal analysis of growth and puberty in 21-hydroxylase deficiency patients. Archives of Disease in Childhood 200287 139-144. (https://doi.org/10.1136/adc.87.2.139)

21 Whitaker MJ, Spielmann S, Digweed D, Huatan H, Eckland D, Johnson TN, Tucker G, Krude H, Blankenstein O \& Ross RJ. Development and testing in healthy adults of oral hydrocortisone granules with taste masking for the treatment of neonates and infants with adrenal insufficiency. Journal of Clinical Endocrinology and Metabolism 2015100 1681-1688. (https://doi.org/10.1210/ jc.2014-4060)

22 Neumann U, Whitaker MJ, Wiegand S, Krude H, Porter J, Davies M, Digweed D, Voet B, Ross RJ \& Blankenstein O. Absorption and tolerability of taste-masked hydrocortisone granules in neonates, infants and children under 6 years of age with adrenal insufficiency. Clinical Endocrinology 201888 21-29. (https://doi.org/10.1111/cen.13447)

23 Neumann U, Braune K, Whitaker MJ, Wiegand S, Krude H, Porter J, Digweed D, Voet B, Ross RJM \& Blankenstein O. A prospective study of children aged 0-8 years with $\mathrm{CAH}$ and adrenal insufficiency treated with hydrocortisone granules. Journal of Clinical Endocrinology and Metabolism 2021106 e1433-e1440. (https://doi.org/10.1210/ clinem/dgaa626)

24 Charmandari E, Brook CG \& Hindmarsh PC. Why is management of patients with classical congenital adrenal hyperplasia more difficult at puberty? Archives of Disease in Childhood 200286 266-269. (https://doi.org/10.1136/adc.86.4.266)

25 Charmandari E, Brook CG \& Hindmarsh PC. Classic congenital adrenal hyperplasia and puberty. European Journal of Endocrinology 2004151 (Supplement 3) U77-U82. (https://doi.org/10.1530/eje.0.151u077)

26 Charmandari E, Hindmarsh PC, Johnston A \& Brook CG. Congenital adrenal hyperplasia due to 21-hydroxylase deficiency: alterations in cortisol pharmacokinetics at puberty. Journal of Clinical Endocrinology and Metabolism 200186 2701-2708. (https://doi.org/10.1210/ jcem.86.6.7522)

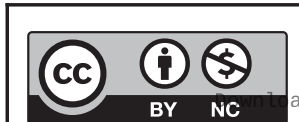

This work is licensed under a Creative Commons Attribution-NonCommercial 4.0 International License. ded from Bioscientifica com at 04/26/2023 01:50:05PM 
27 Bonfig W, Roehl F, Riedl S, Bramswig J, Richter-Unruh A, FrickeOtto S, Hubner A, Bettendorf M, Schonau E, Dorr H, et al. Sodium chloride supplementation is not routinely performed in the majority of German and Austrian infants with classic salt-wasting congenital adrenal hyperplasia and has no effect on linear growth and hydrocortisone or fludrocortisone dose. Hormone Research in Paediatrics 201889 7-12. (https://doi.org/10.1159/000481775)

28 Kourime M, Bryce J, Jiang J, Nixon R, Rodie M \& Ahmed SF. An assessment of the quality of the I-DSD and the I-CAH registries international registries for rare conditions affecting sex development. Orphanet Journal of Rare Diseases 201712 56. (https://doi. org/10.1186/s13023-017-0603-7)

29 Ali SR, Lucas-Herald A, Bryce J \& Ahmed SF. The role of international databases in understanding the aetiology and consequences of differences/disorders of sex development. International Journal of Molecular Sciences 201920 4405. (https://doi.org/10.3390/ ijms20184405)

30 Nordenstrom A, Svensson J, Lajic S, Frisen L, Nordenskjold A, Norrby C, Almqvist C \& Falhammar H. Carriers of a classic CYP21A2 mutation have reduced mortality: a population-based national cohort study. Journal of Clinical Endocrinology and Metabolism 2019 104 6148-6154. (https://doi.org/10.1210/jc.2019-01199)

31 Engberg H, Butwicka A, Nordenstrom A, Hirschberg AL, Falhammar H, Lichtenstein P, Nordenskjold A, Frisen L \& Landen M. Congenital adrenal hyperplasia and risk for psychiatric disorders in girls and women born between 1915 and 2010: a total population study. Psychoneuroendocrinology 201560 195-205. (https://doi. org/10.1016/j.psyneuen.2015.06.017)

Received in final form 21 April 2021

Accepted 28 April 2021

Accepted Manuscript published online 28 April 2021
This work is licensed under a Creative Commons Attribution-NonCommercial 4.0 International License. ded from Bioscientifica.com at 04/26/2023 01:50:05PM via free access 